\title{
Development and Characterization of Polysulfone/Polyvinylidene Flouride Blend Membrane Induced by Delayed Liquid-Liquid Demixing
}

\author{
Ruwanti Dewi Cahya Ningrum $^{\#}$, Nita Kusumawati ${ }^{\#}$ \\ \# Department of Chemistry, Universitas Negeri Surabaya, Surabaya, 60231, Indonesia \\ E-mail:ruwantidcn95@yahoo.com
}

\begin{abstract}
Polysulfone (PSf)-Polyvinylidene fluoride (PVDF) membranes were fabricated via phase inversion method and immersion precipitation technique. In particular, the effect of varied amount of NMP addition into coagulation bath on permeability, mechanical properties, chemical resistance and thermal stability of membranes were investigated. The presence of solvent in coagulation bath caused delayed liquid-liquid demixing that caused increasing chance of disoriented interactions in PSf/PVDF blend membrane thus larger pore and dominated macrovoids membranes resulted. It was found that the increase of solvent addition lead to increasing of flux and decreasing of mechanical strength whereas a remarkably and enhanced chemical resistance has been achieved which showed excellent resistance in $\mathrm{H}_{2} \mathrm{SO}_{4}$ but degraded upon exposure to a concentration of $40 \% \mathrm{NaOH}$ solution. Furthermore, TGA analysis revealed that the membrane exhibit improved thermal stability while the morphology of membrane showed the formation of asymmetry structure.
\end{abstract}

Keywords - PSf/PVDF membrane; delayed liquid-liquid demixing; permeability; chemical resistance; mechanical properties; thermal properties

\section{INTRODUCTION}

Membrane-based processes, with their inherent advantages include the separation can be performed continuously and combined with other separation processes, low enviromental impact, easy scale up and does not require any additional material. Therefore it becomes highly competitive candidate for liquid or gas separations. Polysulfone has excellent chemical resistance almost in the entire range of $\mathrm{pH}(2-13)$ and oxidative medium $(5-7 \%$ hypochlorite, hydrogen peroxide 3-5\%) [1], [2]. Nevertheless, polysulfone (PSf) tend to form symmetry structure which has high mass transfer resistance so the fouling tendency will be higher than asymmetry membrane. A classical way to overcome this issue is by blending it with other polymers which have the potential to form asymmetry structures such as polyvinylidene fluoride (PVDF)

PVDF is resistant to almost all organic acids, inorganic and oxidative medium. However, the excellent chemical stability of PVDF does not particularly apply to strong base solutions or to esters and ketones [3]-[6]. In contrast, polysulfone has good chemical resistance to bases. Reference [6], [7] investigated the chemical stability of PSf/PVDF membranes with composition of
$\mathrm{PSf} / \mathrm{PVDF} / \mathrm{NMP} / \mathrm{NH}_{4} \mathrm{Cl}(\% \mathrm{w} / \mathrm{w} / \mathrm{w}) 12 / 2 / 84 / 2$ in acid and base solutions. The result showed that PSf/PVDF membranes have good resistance in acidic environments. Meanwhile, the membranes showed poor chemical resistance in alkaline environment which is proved by the discolouration became darker where the dehydrofluorination in polymer chain of PVDF caused the formation of $\mathrm{C}=\mathrm{C}$ [3], [8]-[9]. The polymers blending between PSf and PVDF will result new material with improved performance and chemical resistance.

PSf and PVDF membranes are prepared by phase inversion method and immersion precipitation technique due to its ability to form asymmetry structure [6], [10]-[11]. The magnitude of difference between the solubility parameter of solvent and non solvent in this method determine the rate of phase inversion and physical properties of membrane. The addition of solvent into coagulation bath caused lower solubility parameter difference thus delayed liquid-liquid demixing occurs. Reference [12] have prepared polyimide membrane with the addition of DMAc as solvent into coagulation bath containing water as non solvent. The presence of solvent in coagulation bath caused delayed demixing [7], [11]-[13] that established pores in membrane to be denser. Beside that, delayed demixing prevented macrovoids formation. 
This work aimed to investigate the influence of NMP addition into coagulation bath on permeability, mechanical properties, chemical resistance and morphologies of PSf/PVDF membrane. Therefore the permeability, mechanical properties, chemical resistance of membranes as well the morphology were investigated intensively.

\section{MATERIALS AND METHODS}

\section{A. Materials}

Research equipment include: glass tools (pyrex), Ohaus PAJ1003 analytical balance, NESCO LAB MS-H280-Pro magnetic stirrer with temperature control for mixing the membrane material, casting knife with a thickness of $0.8 \mathrm{~mm}$, coagulation bath (self-made) with a volume of $250 \mathrm{~mL}$, and thermometer. While the research instruments include: deadend membrane reactors (self-made) which is connected with compressor as a pressure source (maximum pressure of 6 bar), Nicolet IS10 Thermo Fourier Transform Infra Red (FTIR), Zeiss EVO MA10 Scanning Electron Microscopy (SEM), RCT/10KN/AF TOYO SEIKI Strograph, Perkin Elmer STA-6000 Differential Scanning Calorymetry (DSC)Thermal Gravimetric Analysis (TGA).

Materials research include: Polysulfone $(\mathrm{d}=1.24 \mathrm{~g} / \mathrm{mL}$ at $25^{\circ} \mathrm{C}, \mathrm{MW}=35000 \mathrm{~g} / \mathrm{mole}$, Sigma Aldrich), Polyvinylidene fluoride (PVDF) $\left(\mathrm{MW}=354000 \mathrm{~g} /\right.$ mole, Aldrich), $\mathrm{NH}_{4} \mathrm{Cl}(\geq$ 99.5\%, Riedel De haen), N-Methyl-2-pyrrolidone ( $\geq 99.7 \%$ Sigma Aldrich, MW = $99.13 \mathrm{~g} / \mathrm{mole})$, distilled water, sulfuric acid $\left(\mathrm{H}_{2} \mathrm{SO}_{4} \geq 98 \%\right.$, Ajax Finichem Pty Ltd.), $\mathrm{NaOH}$ ( $\geq 98 \%$, Sigma Aldrich), and gauze fabric (Kasa Husada Indonesia, 254 mesh).

\section{B. Preparation of PSf/PVDF Membranes}

The PSf/PVDF membranes with casting solution composition of (PVDF/PSF/NMP/NH4Cl) (\%w/w) 8/6/84/2 were prepared by phase inversion method. In order to obtain homogeneous solution, PSf and $\mathrm{NH}_{4} \mathrm{Cl}$ were dissolved in NMP and then the solution has stirred with a magnetic stirrer for 105 minutes at $60{ }^{\circ} \mathrm{C}$ subsequently followed by the addition of PVDF with stirring time for 30 minutes which is based on a research by [6], [7]. The homogeneous solution was then casted onto a gauze fabric with a thickness of 0.8 $\mathrm{mm}$ and settled for 5 minutes. Furthermore, the casting solution was immersed in a coagulation bath containing of distilled water and varied NMP addition of $0.5 \mathrm{~mL} ; 1 \mathrm{~mL}$; $1.5 \mathrm{~mL} ; 2 \mathrm{~mL} ; 2.5 \mathrm{~mL}$ with immersion temperature of $80^{\circ} \mathrm{C}$. A solid PSf/PVDF membrane then washed by distilled water for 1 minute to remove remnants of solvent. After that, the solid membrane dried in the open air for 24 hours.

\section{Membrane Characterization}

PSf-PVDF membrane characterization include chemical characterization, mechanical characterization and physical characterization. Chemical characterization was accomplished using FTIR to ensure that the composite membrane of PSf/PVDF was formed by identifying typical functional groups of PSf and PVDF on PSf-PVDF membrane.

Mechanical characterization was carried out with strograph to measure the mechanical properties of membranes. Based on stress and strain values, mechanical properties of membranes can be determined by equation (1).

$$
Y=\frac{a}{\varepsilon}
$$

where Y is Young's modulus $\left(\mathrm{N} / \mathrm{m}^{2}\right)$; $\sigma$ is stress; $\varepsilon$ is strain Physical characterization of the membrane was conducted to observe the cross sectional and surface morphologies. As comparison, PVDF membrane and PSf membrane with composition of $14 / 84 / 2$ and $14 / 84 / 2$ respectively were characterized.

\section{Permeability Test of PSf/PVDF Membrane}

The permeability of PSf/PVDF membranes were determinated by measuring flux. According to reference [14], [15] membranes with diameter of about $\pm 4,8 \mathrm{~cm}$ were examined at constant working pressure of $1 \mathrm{bar}\left(\mathrm{kg} / \mathrm{cm}^{3}\right)$ as a driving force. Furthermore, according to the time required to pass through the membrane, volume of feed solution and surface area of membranes, flux can be calculated by equation (2).

$$
l=\frac{V}{A \cdot t}
$$

where $\mathrm{J}$ is flux $\left(\mathrm{L} / \mathrm{m}^{2} \cdot \mathrm{h}^{-1}\right)$; $\mathrm{V}$ is volume of feed solution $(\mathrm{L})$; $A$ is surface area $\left(\mathrm{m}^{2}\right) ; \mathrm{t}$ is required time for feed solution through membrane $(\mathrm{h})$.

\section{E. PSf/PVDF Membranes Chemical Resistance}

PSf/PVDF membranes were immersed in various concentrations of $\mathrm{H} 2 \mathrm{SO} 4(6 \% ; 20 \% ; 30 \% ; 60 \%$; 96\%; 98\%) and $\mathrm{NaOH}(0,15 \% ; 1,5 \% ; 15 \% ; 40 \% ; 60 \% ; 80 \%)$ for 24 hours [5]-[8]. Furthermore, in order to identify any changes of immersed membranes, the functional groups of membranes were analyzed using FTIR.

\section{F. PSf/PVDF Membranes Thermal Properties}

The membrane was characterized using DSC-TGA with heating temperature from $60{ }^{\circ} \mathrm{C}$ to $200{ }^{\circ} \mathrm{C}$ at a rate of $10^{\circ} \mathrm{C}$ min-1 to determine membrane thermal stability. As comparison, PVDF membrane and PSf membrane with composition of $14 / 84 / 2$ and $14 / 84 / 2$ respectively were characterized.

\section{RESULTS AND DISCUSSION}

\section{A. PSf/PVDF Composite Membrane Preparation}

In this study membranes were fabricated using phase inversion methods because of its simple process and flexible production scale. The most frequently used technique of phase inversion is immersion precipitation. Asymmetry structure of membranes which is a main goal in this research can be generated through such technique. Therefore in this study, the fabrication of PSf/PVDF using phase inversion by immersion precipitation technique where solvent has an important role hence through proper selection of solvent, the high polymer chain mobility could be maintained, which is directly influenced by both polymer-solvent and polymerpolymer interactions. When polymer molecules dissolve easily in a good solvent, a uniformly distributed polymer configuration could be formed. NMP has smaller difference 
solubility parameter to PSf and PVDF compared with DMAc or DMF as listed on Table 1 therefore NMP has better ability to dissolve PVDF and PSf as reported by Reference [16][20].

TABLE I

HANSEN SOLUBILITY PARAMETER

\begin{tabular}{|c|l|c|c|c|c|}
\hline No. & Material & $\begin{array}{c}\delta_{\mathrm{d}} \\
\left(\mathrm{MPa}^{1 / 2}\right)\end{array}$ & $\begin{array}{c}\delta_{\mathrm{p}} \\
\left(\mathrm{MPa}^{1 / 2}\right)\end{array}$ & $\begin{array}{c}\delta_{\mathrm{h}} \\
\left(\mathrm{MPa}^{1 / 2}\right)\end{array}$ & $\begin{array}{c}\delta_{\mathrm{t}} \\
\left(\mathrm{MPa}^{1 / 2}\right)\end{array}$ \\
\hline 1 & PVDF & 16 & 14.3 & 23.9 & 32.12 \\
\hline 2 & PSf & 19.7 & 8.3 & 8.3 & 22.93 \\
\hline 3 & NMP & 18 & 12.3 & 7.2 & 22.96 \\
\hline 4 & DMAc & 16.8 & 11.5 & 10.2 & 22.77 \\
\hline 5 & DMF & 17.4 & 13.7 & 11.3 & 24.8 \\
\hline 6 & NMP & 18 & 12.3 & 7.2 & 22.96 \\
\hline 7 & Water & 12.2 & 22.8 & 40.4 & 48.0 \\
\hline
\end{tabular}

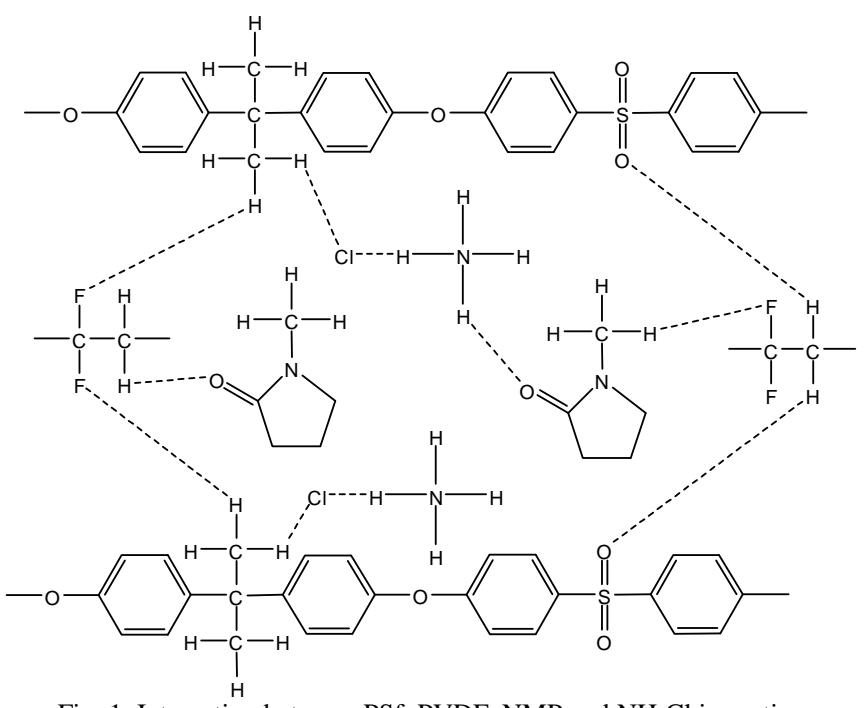

Fig. 1 Interaction between $\mathrm{PSf}, \mathrm{PVDF}, \mathrm{NMP}$ and $\mathrm{NH}_{4} \mathrm{Cl}$ in casting solution

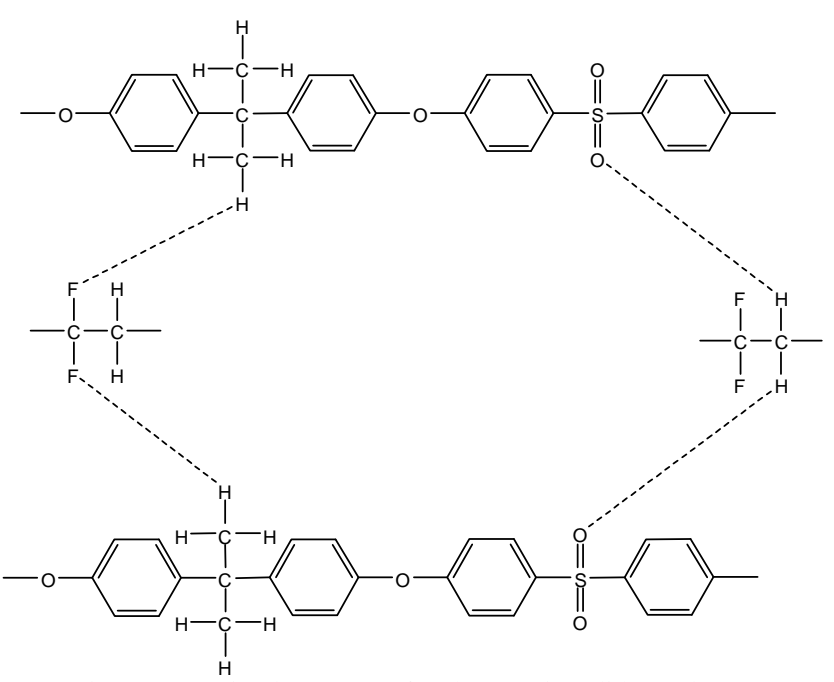

Fig. 2 Interaction between PSf and PVDF in solid membrane
In order to represent homogeneous casting solution, stirring temperature of $60^{\circ} \mathrm{C}$ was applied based on a research by reference [6], [7] that discovered that polysulfone can dissolve well in such temperature. The first stage to represent solid membrane is casting process using casting knife on a coated glass plate by gauze fabric as a supporting layer and then allowed to stand for 5 minutes to remove trapped air bubbles in casting solution. The next stage is phase inversion induced by immersion precipitation technique using water. Water is well known as harsh non solvent. The magnitude of solubility parameter difference between NMP and water determined the rate of phase inversion as well as the physical properties and permeability of membrane. The solubility parameter difference between NMP and water is $25.04 \mathrm{MPa}^{1 / 2}$ as listed in table 1 . The addition of NMP into coagulation bath lower the solubility parameter difference between solvent and non solvent in order to reduce macrovoid formation as reported by reference [21] where the use of NMP as solvent and water as non solvent in PSf/PVDF membrane preparation was dominated by macrovoid due to large solubility parameter difference between solvent and non solvent thus phase inversion occured instantaneously and uncontrolled.

The presence of NMP in coagulation bath caused delayed liquid-liquid demixing which resulted on decreasing of diffusion rate between solvent and non solvent therefore the phase inversion lasts longer. Similar finding was obtained by [12] demonstrated the addition of DMAc as solvent into a coagulation bath containing water as non solvent in polyimide membrane preparation. The results showed that phase inversion occured lasts longer.

Interactions between constituent polymer of membrane in casting solution and interactions that occurs when solid PSf/PVDF membrane obtained based on hansen solubility parameter include permanent dipole, temporary dipole and hydrogen bonding are shown in Fig. 2 and Fig. 3.

\section{B. Membrane Characterization}

1) Chemical Characterization: The chemical composition of PSf-PVDF membrane was detected via FTIR anlysis to ensure that the composite membrane of PSf/PVDF has been formed as shown in Fig. 4 and Table 2 presents typical peaks data of PVDF and PSf in PSf/PVDF membrane.

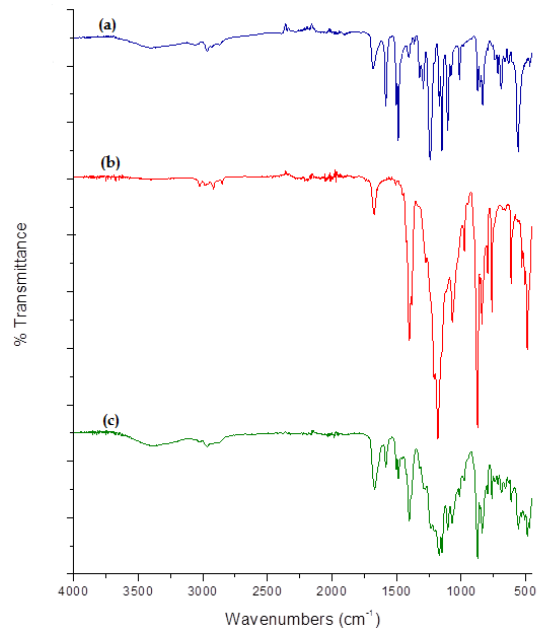

Fig. 3 Infrared spectra of : (a) PSf membrane, (b) PVDF membrane and (c) PSf-PVDF membrane 
TABLE II

TyPiCAL PEAKS OF PSF/PVDF MEMBRANE

\begin{tabular}{|c|c|c|c|}
\hline No. & Membrane & $\begin{array}{c}\text { Wavenumbers } \\
\left(\mathrm{cm}^{-1}\right)\end{array}$ & $\begin{array}{c}\text { Functional } \\
\text { Groups }\end{array}$ \\
\hline \multirow[b]{2}{*}{1} & \multirow[b]{2}{*}{ PVDF } & 1402.33 & C-H alkane \\
\hline & & $\begin{array}{c}1169.57- \\
1013.55\end{array}$ & $\mathrm{C}-\mathrm{F}$ \\
\hline \multirow{2}{*}{2} & \multirow{2}{*}{ PSf } & $\begin{array}{c}1670.73- \\
1486.80\end{array}$ & $\mathrm{C}=\mathrm{C}$ aromatic \\
\hline & & 2964.30 & $\begin{array}{c}\mathrm{C}-\mathrm{H} \\
\text { alkane/aromatic }\end{array}$ \\
\hline \multirow{5}{*}{3} & \multirow{5}{*}{ PSf/PVDF } & $3000-2850$ & $\begin{array}{c}\mathrm{C}-\mathrm{H} \\
\text { alifatic/alkane }\end{array}$ \\
\hline & & $1680-1640$ & $\mathrm{C}=\mathrm{C}$ alkene \\
\hline & & $1650-1450$ & $\mathrm{C}=\mathrm{C}$ aromatic \\
\hline & & $1140-1120$ & $\mathrm{C}-\mathrm{O}$ ether \\
\hline & & $1100-1000$ & $\mathrm{C}-\mathrm{F}$ \\
\hline
\end{tabular}

In Table 2, It can be observed that typical peaks of PVDF and PSf were observed in infra red spectra of PSf/PVDF. Therefore the composite membrane of PSf/PVDF has been successfully prepared.

2) Mechanical Characterization: Mechanical properties testing of PSf/PVDF membranes is necessary in order to measuring the force required to elongate a specimen to breaking point.

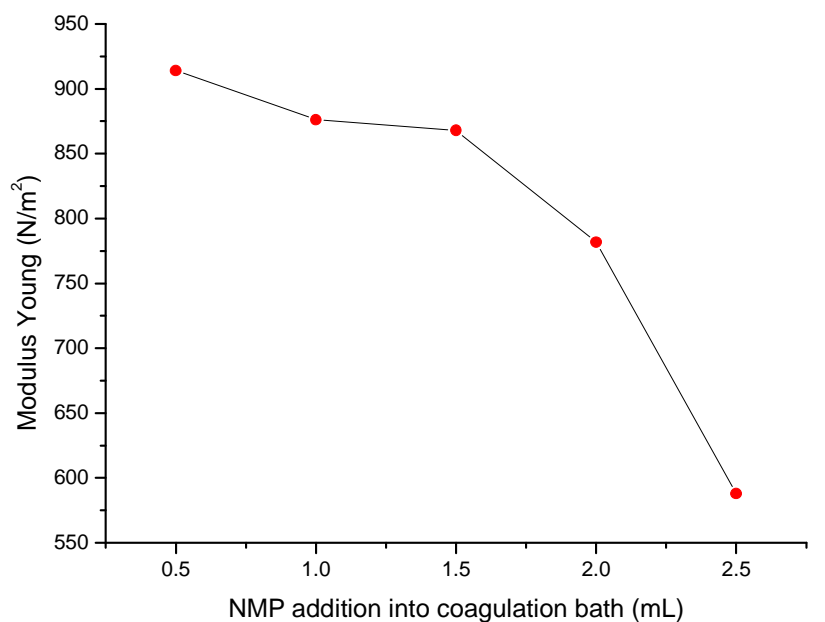

Fig. 4 Mechanical strength graph of PSf/PVDF membrane

According to Fig. 6, it was observed that mechanical properties of PSf/PVDF membranes decreased in line with increasing amount of NMP in coagulation bath. The presence of NMP in coagulation bath tend to dissolve PSf than PVDF considering its smaller solubility parameter difference which caused the formation of PVDF framework while rearrangement of PSf occured and tend to conform PVDF framework that resulted the formation of macrovoids which led to reduction of mechanical strength.

3) Physical Characterization: In order to evaluate the effect of NMP addition into coagulation bath on physical properties of membrane, analysis of surface and cross sectional morphologies of PSf/PVDF membrane was accomplished using SEM. As comparison, PVDF membrane and PSf membrane with composition of 14/84/2 respectively analyzed as control.
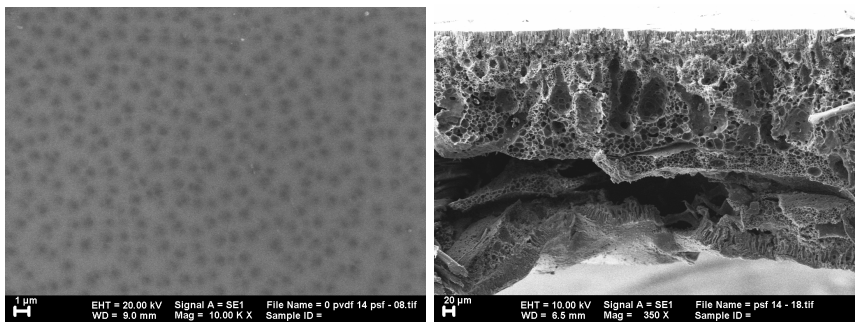

(a)
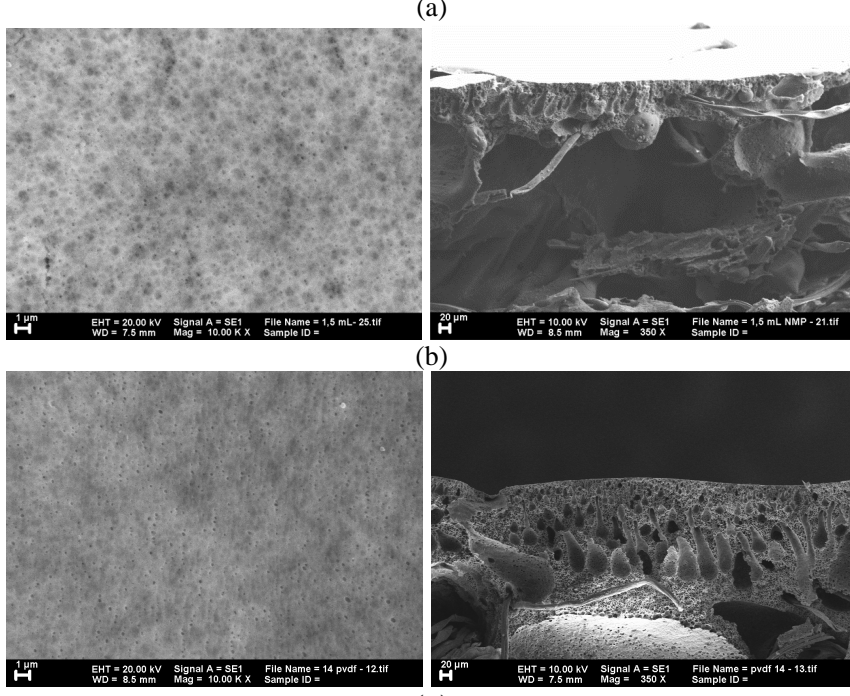

(c)

Fig. 5 SEM images of surface and cross section morphology: (a) PSf membrane; (b) PSf/PVDF membrane; (c) PVDF membrane

PSf/PVDF membrane with the addition of $1.5 \mathrm{~mL}$ of NMP into coagulation bath resulted lower porosity and smaller pore size than PSf membrane as shown in Fig. 9. The PSf/PVDF membrane exhibit higher porosity and larger pore size compared to PVDF membrane considering the size of PSf monomer chain which is larger than PVDF thus PSf membrane exhibit bigger pore size compared with PVDF membrane. Meanwhile, the pore size of PSf/PVDF membrane is a combination of both. In addition, the occurance of delayed liquid-liquid demixing as a result of NMP addition into coagulation bath provided more time for the interaction between atoms of membrane constituent monomers.

Nevertheless, as a result of the closeness between the solubility parameter of NMP in coagulation bath with PSf in casting solution caused the inhibition on coagulation process of PSf. This is certainly affected the formation of PSf framework where PSf tend to conform PVDF framework that was formed at first therefore a lot of empty space resulted which is known as macrovoids.

Meanwhile, the cross sectional morphology of PSf membrane showed thick sponge pore on top layer that caused low permeability thus the time required for feed solution through a membrane took longer although the pore size on surface morphology is quite large. On the other hand, PVDF membrane is dominated by thin sponge pore on top layer hence large permeability resulted. However PSf/PVDF membrane showed thinner top layer than PSf membrane but thicker compared with PVDF membrane eventhough macrovoid was observed as a result of disoriented interactions. 


\section{PSf/PVDF Membrane Permeability Test}

Permeability of PSf/PVDF membranes can be measured from flux using dead-end filtration system. The flux indicates the volume of permeate crossing a unit area per unit time.

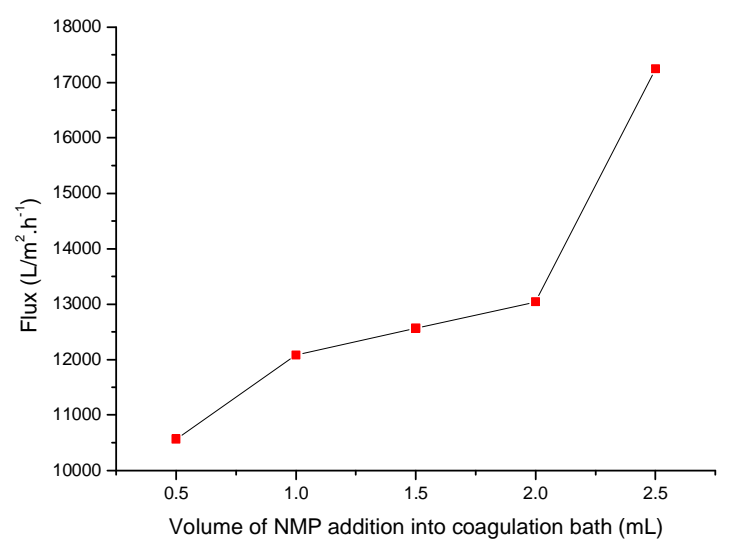

Fig. 6 Permeability graph of PSf-PVDF membranes

The addition of various amount of NMP into coagulation bath exhibits distinct flux values as shown in Fig. 5. Increasing amount of NMP addition into coagulation bath increased the premeability. When NMP was added into coagulation bath, NMP tend to dissolve PSf compared with PVDF due to its smaller solubility parameter difference than PVDF hence the PVDF framework formed first and rearrangement of PSf occured. Since interactive atoms position between PSf and PVDF were uncertain thus disoriented interactions resulted which then led to formation of macrovoids. As a result, the rate of feed solution crossing the membrane increased.

\section{PSf/PVDF Membranes Chemical Resistance}

1) Chemical Resistance in acidic environment: The change colour of immersed membranes in various concentration of $\mathrm{H}_{2} \mathrm{SO}_{4}$ solution was not recognized. Nevertheless to establish significant changes in chemical composition of PSf/PVDF membrane was detected via FTIR analysis and Table 3 presents typical peaks data of PSf and PVDF in PSf/PVDF membrane.

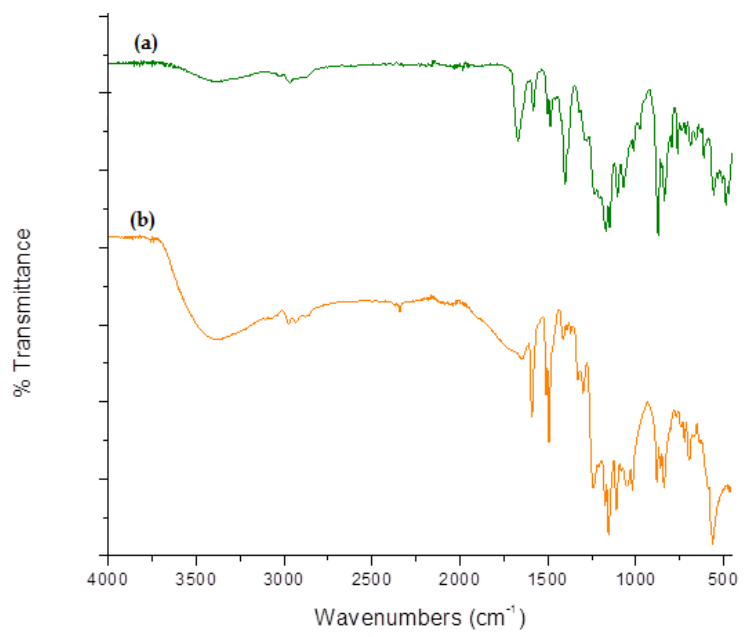

Fig. 7 Infrared spectra of PSf/PVDF membrane: (a) before being immersed in $98 \%$ of $\mathrm{H}_{2} \mathrm{SO}_{4}$; (b) after being immersed $98 \%$ of $\mathrm{H}_{2} \mathrm{SO}_{4}$
TABLE III

TYPICAL PEAKS OF PSF/PVDF MEMBRANE

\begin{tabular}{|c|c|c|c|c|}
\hline No. & $\begin{array}{c}\text { Wavenumbers } \\
\left(\mathbf{c m}^{-1}\right)\end{array}$ & $\begin{array}{c}\text { Functional } \\
\text { Groups }\end{array}$ & $\begin{array}{c}\text { Before } \\
\text { Immersion }\end{array}$ & $\begin{array}{c}\text { After } \\
\text { Immersion }\end{array}$ \\
\hline 1 & $3600-3200$ & -OH alcohol & 3389.08 & - \\
\hline 2 & $3000-2850$ & $\begin{array}{c}\text { C-H } \\
\text { alifatic/alka } \\
\text { ne }\end{array}$ & 2964.30 & - \\
\hline 3 & $1680-1640$ & C=C alkene & 1670.73 & - \\
\hline & & C=C & $1583.94 ;$ & $1583.80 ;$ \\
4 & $1650-1450$ & aromatic & $1503.76 ;$ & $1503.53 ;$ \\
& & C-O ether & 11486.80 & 1486.72 \\
\hline 5 & $1140-1120$ & & $1104.56 ;$ & $1103.60 ;$ \\
\hline & & & $1070.48 ;$ & $1043.33 ;$ \\
6 & $1100-1000$ & C-F & 1013.55 & 1012.62 \\
\hline
\end{tabular}

It is well known that PVDF has better chemical resistance in acidic environment than PSf, as shown in Table 3 where any changes of PSf and PVDF typical functional groups on infrared spectra of PSf/PVDF membrane was undetected.

2) Chemical Resistance in alkaline environment: After 24 hours of immersion in various concentration of $\mathrm{NaOH}$ solution, the discolouration was found in membranes after being immersed in $60 \%$ and $80 \%$ of $\mathrm{NaOH}$. The membranes turned into brown and finally black due to increasing concentration of $\mathrm{NaOH}$ solution. The colour change indicated dehydrofluorination reaction which is supported by the infrared spectra of PSf/PVDF membrane that indicate loss of -HF group from PVDF, as shown in Figure 8. It also showed that PSf has better resistance in alkaline environment compared with PVDF.

Similar findings were obtained by [5], [22]-[23]. It was observed that PVDF membrane can be attacked and degraded even to a low concentration of $\mathrm{NaOH}$ solution. However, the discolouration of immersed membranes in $0.15 \%, 1.5,15 \%$ and $40 \%$ wt $\mathrm{NaOH}$ was not observed. In order to establish significant changes in chemical composition of PSf/PVDF membrane was detected via FTIR analysis and Table 4 presents typical peaks data of PVDF and PSf in PSf/PVDF membrane.

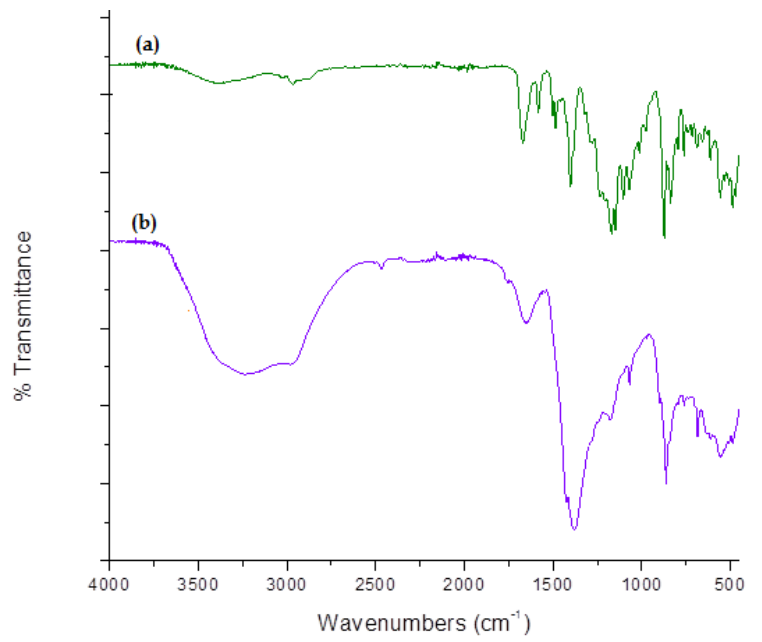

Fig. 8 Infrared spectra of PSf/PVDF membrane: (a) before being immersed in $80 \%$ of $\mathrm{NaOH}$; (b) after being immersed $80 \%$ of $\mathrm{NaOH}$ 
TABLE IV

TyPiCAL PEAKs OF PSF/PVDF MEMBRANE

\begin{tabular}{|c|c|c|c|c|}
\hline No. & $\begin{array}{c}\text { Wavenumbers } \\
\left(\mathbf{c m}^{-\mathbf{1}}\right)\end{array}$ & $\begin{array}{c}\text { Functional } \\
\text { Groups }\end{array}$ & $\begin{array}{c}\text { Before } \\
\text { Immersion }\end{array}$ & $\begin{array}{c}\text { After } \\
\text { Immersion }\end{array}$ \\
\hline 1 & $3600-3200$ & $-\mathrm{OH}$ alcohol & 3389.08 & 3231.35 \\
\hline 2 & $3000-2850$ & $\begin{array}{c}\mathrm{C}-\mathrm{H} \\
\text { alifatic/alkane }\end{array}$ & 2964.30 & - \\
\hline 3 & $1680-1640$ & $\mathrm{C}=\mathrm{C}$ alkene & 1670.73 & 1654.69 \\
\hline \multirow{2}{*}{4} & $1650-1450$ & C=C aromatic & $\begin{array}{c}1583.94 ; \\
1503.76 ;\end{array}$ & 1378.81 \\
& & & 1486.80 & \\
\hline 5 & $1140-1120$ & C-O ether & 1149.15 & - \\
\hline & & & $1104.56 ;$ & $1070.48 ;$ \\
& $1100-1000$ & C-F & 1013.55 & 1068.35 \\
\hline
\end{tabular}

Fourier transform infra-red (FTIR) result showed the decrease of -HF peak intensity was observed while the formation of double bond carbon due to the elimination of HF molecules occured.

\section{E. PSf/PVDF Membranes Thermal Properties}

Thermal stability of PSf/PVDF membrane was characterized using DSC-TGA to determine membrane thermal stability. As comparison, PVDF membrane and PSf membrane with composition of $14 / 84 / 2$ and $14 / 84 / 2$ respectively were characterized.

According to Fig. 9, the weight loss increased in line with increasing of temperature. The weight loss under $120{ }^{\circ} \mathrm{C}$ is mainly attributed by free-water loss while at a temperature range between $120{ }^{\circ} \mathrm{C}$ and $200{ }^{\circ} \mathrm{C}$, the polymer matrix started decomposing where bond breakage occured.

It was observed that PSf/PVDF membrane resulted higher thermal stability than PSf membrane with a weight loss of $4.23 \%, 6.93 \%$ respectively. This is due to the occurance of $\mathrm{C}-\mathrm{S}$ bond breaking in polysulfone. On the other hand, PVDF membrane represented better thermal resistance of $3.24 \%$ compared with PSf/PVDF membrane where the loss of hydrogen fluoride (HF) or dehydrofluoronation took place. It was known that $\mathrm{C}-\mathrm{S}$ bond in PSf has lower bond dissociation energy than C-F in PVDF hence PSf exhibit lower thermal stability than PVDF. Therefore, the presence of PVDF in PSf/PVDF membrane enhanced the thermal stability.

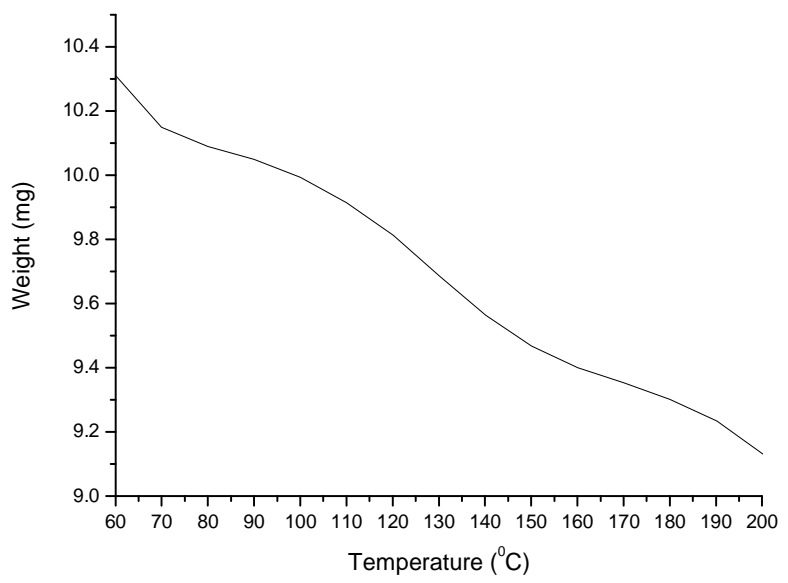

(a)

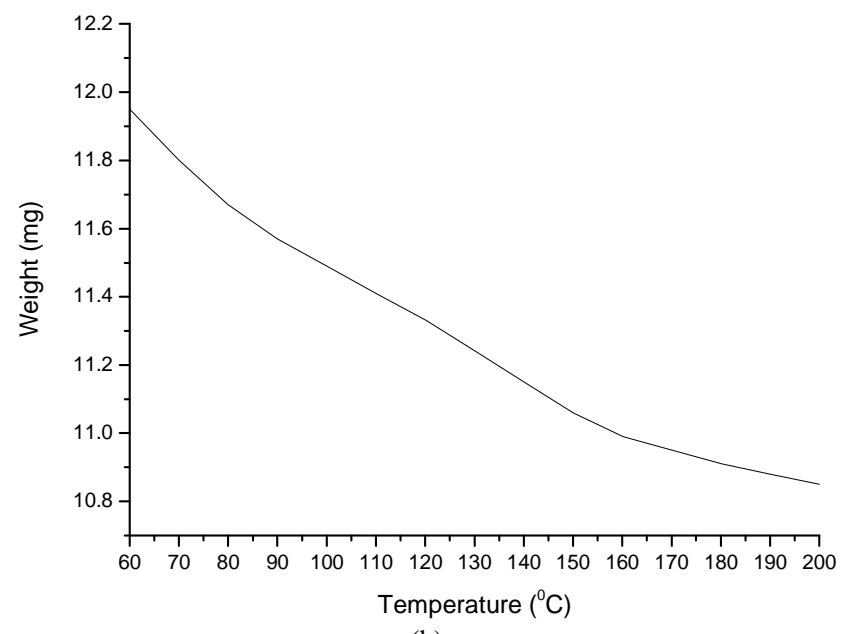

(b)

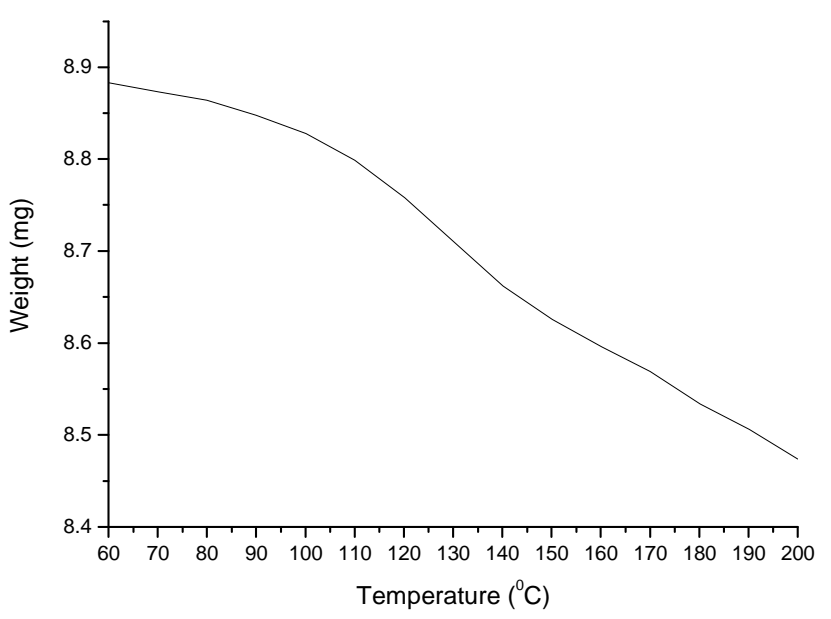

(c)

Fig. 9 TGA curves of: (a) PSf membrane; (b) PSf/PVDF membrane; (c) PVDF membrane

\section{CONCLUSIONS}

In this study, effects of NMP addition into coagulation bath on permeability, chemical resistance, mechanical and thermal stability as well membrane morphology were studied. The presence of NMP in coagulation bath resulted delayed liquid-liquid demixing and rearrangement of PSf hence the occurance of disoriented interactions in PSf/PVDF membrane increased which then led to represent larger pore size and dominated macrovoids membrane with high permeability and low mechanical strength. However, PSf/PVDF membrane exhibit outstanding chemical resistance in $\mathrm{H}_{2} \mathrm{SO}_{4}$ but degraded in $40 \%$ of $\mathrm{NaOH}$ solution. In addition, PSf/PVDF membrane resulted excellent thermal stability. 


\section{REFERENCES}

[1] S. Nunes, and K. Peinemann, Membrane Technology in the Chemical Industry, 2nd ed., Wiley-Vch Verlag GmbH \& Co. KGaA, 2006.

[2] S. I. Voicu, F. Aldea, M. Radut, and G. Nechifor, "Nanostructured Polysulfone Composite Membranes," UPB Sci Bull Series B, vol 70, 2008.

[3] F. Liu, A. N. Hashim, Y. Liu, M. R. M. Abed, K. Li, "Progress in the Production and Modification of PVDF Membranes," Journal Of Membrane Sciences, vol 375, pp.1-27, 2011.

[4] Zeman and Zydney, Microfiltration and Ultrafiltration: Principles and Applications, New York: Marcel Dekker, 1996.

[5] M. F. Rabuni, N. M. N. Sulaiman, N. A. Hashim, "A Systematic Assessment Method for the Investigation of the PVDF Membrane Stability," Desalination and Water Treatment, 2015.

[6] N. Kusumawati, T. Koestari, S. Muslim, "The Development of a New Polymer Membrane: PSf/PVDF Blended Membrane”, Research Journal Of Phatmaceutical, Biological and Chemical Sciences, vol. 7(4), pp. 69-77, 2016

[7] N. Kusumawati, T. Koestari, M. Monica, "The Influence of Casting Solution Composition and Stirring Condition Against Mechanical Strength and Performances of Polyvinylidene Flouride (PVDF) Polysulfone (Psf) Composite Membrane on Textile Industrial Wastewater Treatment," Research Journal Of Phatmaceutical, Biological and Chemical Sciences, vol 6 (1), pp. 271-280, 2015.

[8] M. F. Rabuni, N. M. N. Sulaiman, M. K. Aroua, N. A. Hashim, "Effects of Alkaline Environments at Mild Conditions on the Stabilityof PVDF Membrane: An Experimental Study," Industrial and Engineering Chemistry Research, vol. 52, pp. 15874-15882, 2013.

[9] G. J. Ross, J. F. Watts, M. P. Hill, P. Morrissey, "Surface modification of poly(vinylidene fluoride) by alkaline treatment," Process modification by the use of phase transfer catalysts, Polymer, vol. 42, pp. 403-413, 2001.

[10] S. K. Yong, J. K. Hyo, Y. K. Un, “Asymmetric Membrane Formation Via Immersion Precipitation Method," Journal of Membrane Science. vol. 60, pp. 219-232, 1987.

[11] M. Mulder, Basic principle of Membrane Technology, London: Kluwer Academic, 1996.

[12] K. Y. Chun, S. H. Jang, H. S. Kim, Y. W. Kim, H. K. Han, Y.I. Joe, "Effects of Solvent on the Pore Formation in Asymmetric 6FDA4,4'ODA Polyimide Membrane: Terms of Thermodynamics, Precipitation Kinetics, and Physical Factors," Journal of Membrane Science, vol. 169, pp. 197-214, 2000.
[13] J. R. Reynolds, and T. A. Skotheim, Conjugated Polymers: Processing and Applications, Florida: CRC Press, 2007.

[14] N. Kusumawati, A. Wijiastuti, A. B. Santoso, "Manufacture of PVDF-Kitosan Composite Membrane and its Utilization in Batik Industrial Wastewater Treatment," Research Journal Of Phatmaceutical, Biological and Chemical Sciences, vol. 6(2), pp. 495-503, 2015.

[15] K. D. A. Maharani, N. Kusumawati, “ The Effect of Casting Solution and Non Solvent Composition on the Performance of Polysulfone Membranes against Chromium (VI)", Research Journal Of Phatmaceutical, Biological and Chemical Sciences, vol. 7(2), pp. 495-504, 2016.

[16] A. L. Ahmad, N. Ideris, B. S. Ooi, S. C. Low, A. Ismail, " Influence of Polymer Concentration on PVDF Membrane Fabrication for Immunoassay Analysis”, Journal of Applied Sciences, vol. 14, pp. 1299-1303, 2014.

[17] A. Bottino, G. C. Roda, G. Capannelli, S. Munari, " The formation of microporous polyvinylidene diflouride membranes by phase separation”, Journal of Membrane Science, vol. 57, pp. 1-20, 1991.

[18] M. P. Chenar, H. Rajabi, M. Pakizeh, M. Sadeghi, A. Bolverdi, "Effect of solvent type on the morphology and gas permeation properties of polysulfone-silica nanocomposite membranes", Journal of Polymer Research, vol. 20, pp. 216, 2013.

[19] S. H. Chen, R. M. Liou, J. Y. Lai, C. L. Lai, "Effect of the polarity of additional solvent on membrane formation in polysulfone/ $N$-methyl2-pyrrolidone/water ternary system", Europe Polymer Journal, vol. 43, pp. 3997, 2007.

[20] W. H. Lau, M. Guiver, T. Matsuura, " Phase separation in polysulfone/solvent/water and polyethersulfone/solvent/water systems", Journal of Membrane Science, vol. 59, pp. 3215-3221, 1991.

[21] G. R. Guilen, Y. Pan, M. Li, E. M. V. Hoek, “ Preparation and characterization of membranes formed by non solvent induced phase separation: a review", Industrial and Engineering Chemistry Research Journal, vol. 50 (7), pp. 3798-3817, 2011.

[22] L. Tao, Z. J. Wei, W. D. Rui, H. P. Hao, D. Z. Min, "Dielectric Properties of Chemical Dehydrofluorinated Poly(vinylidene fluoride)", Journal of Advanced Physics, vol. 4 (4), pp. 380-383, 2015 .

[23] N. A. Samsure, N. A. Hashim, N. M. N. Sulaiman, C. Y. Chee, "Alkaline etching treatment of PVDF membrane for water filtration", Royal Society of Chemistry Journal, vol. 26, pp. 22153-22160, 2016. 